2007

\title{
Electronic signatures for copyright in the UK: a solution to the "holy grail" of document delivery
}

Titley, Graham

http://hdl.handle.net/10026.1/9627

10.1108/02641610710728140

Interlending and Document Supply

EMERALD GROUP PUBLISHING LIMITED

All content in PEARL is protected by copyright law. Author manuscripts are made available in accordance with publisher policies. Please cite only the published version using the details provided on the item record or document. In the absence of an open licence (e.g. Creative Commons), permissions for further reuse of content should be sought from the publisher or author. 


\title{
Electronic Signatures for Copyright in the UK: a solution to the 'holy grail' of document delivery
}

Graham Titley

Document Delivery and Copyright Librarian

University of Plymouth, Plymouth, UK.

\begin{abstract}
Since 1988, when the current Copyright Design and Patents Act (1988) was passed into law, document delivery of photocopies in the United Kingdom has been burdened by the weight of the paper trail - having to obtain a personally signed Copyright Declaration each and every time a user asks a prescribed library ${ }^{1}$ to obtain a photocopy from another library, and then having to store the declarations for 6 years plus one day from the end of the year in which it was signed! Hopes were raised that, with the adoption of the Electronic Signature Regulations in 2002 (Statutory Instrument 2002, No. 318), this paper mountain could be reduced to electronic storage. These hopes were quickly dashed when the gamut of professional opinion and advice railed against the simple adoption of Personal Identification Numbers (PINs). They were deemed to be insufficient, in and of themselves, to meet the definition of an advanced electronic signature as provided in the regulations. This article describes the drivers for change that influenced a revisiting of the issue of electronic signatures for copyright by the University of Plymouth library service, and how an electronic 'request-to-delivery' service has been achieved, reducing ILL turn around times for photocopies from an average of 7 days to an average of 2.5 days.
\end{abstract}

\footnotetext{
${ }^{1}$ A prescribed library in the meaning of the 1988 Act is one entitled to engage in document delivery acticity without incurring copyright fees by using the Library Priivilage provisions of the Act. This is a revised author's draft of an article published in the Emerald journal 'Interlending and Document Supply 2007 vol 35 issue 2 pages 15-20. DOI: http://dx.doi.org/10.1108/02641610710728140
} 


\section{Some background}

The University of Plymouth was invested in 1992 to build upon the solid educational foundations in the South West provided by its forebears, Plymouth Polytechnic and Polytechnic of the South West. The current Vice Chancellor, Roland Levinsky, has overseen a tremendous period of change and development in the organisation and its estate. By Summer 2008 these changes will result in the closure of all outlying smaller campuses (Seale Hayne, 2005; Exeter, 2007; Exmouth, 2008) and the centralisation of all teaching and learning on Plymouth's city centre campus. To accommodate the staff and students from these smaller campuses, a huge building programme has been undertaken at Plymouth to renew and expand the campus, a programme that has already delivered some award listed buildings and an expanded library space.

Concurrent to this, an organisational restructuring was also taking place which has resulted in the merger of Information Services (Library) with Information Technology and Communications (Computing and Networks) to form the Information and Learning Services division (ILS). Within the new division further restructuring saw the development of a more focused, team-based, structure moving away from the former subject-based arrangement. Finally, in response to the changes in teaching and learning methods (e-learning; self-directed learning; group learning; distance learning etc), the library service also reviewed how information was being delivered, how the electronic element of the resources could be developed and promoted, and how suitable the library systems were to meet the demands of the twenty-first century student. It was these changes that started us on the road to This is a revised author's draft of an article published in the Emerald journal 'Interlending and Document Supply 2007 vol 35 issue 2 pages 15-20. DOI: http://dx.doi.org/10.1108/02641610710728140 
ILDS 35.1 Titley rev 30.10.06

electronic signatures.

\section{Software Change}

By 2002/03 it had become apparent that the current library management system (LMS) 'Libertas' was not suitable as a basis for the development of electronic services. The vendor had announced that they had no plans to upgrade the system from its current DOS-based platform to a more user-friendly one, and this decision clearly hampered ILS's move towards the delivery of an integrated resource management system and a more accessible OPAC. So the search began for a replacement.

Libertas did 'handle', after a fashion, ILLs electronically_after a fashion. It provided a means by which requests could be stored and viewed by users and it provided a means by which requests could be sent electronically to the British Library (BL). Everything else required manual inputting. The process in place would be one familiar to many readers: -

- The user completed a request form, signing the declaration on the reverse (and, for certain categories of student, getting the lecturer to countersign the request) before submitting it to the library.

- The form was passed to the subject team for bib-checking and resource checking (checked against catalogue, any electronic resources and the internet, including BL's catalogue).

- Upon completion the form was passed to the ILL Team who entered the request details into Libertas, which would then send them to the British Library (BLDSC) as a batch file around midnight every day. 
- Incoming supplied items arrived via the post and the receipt of the item was recorded on the Libertas record by an ILL operator. The user would then be emailed, and the item placed at the library counter for collection. BLDSC 'Replies', which gives the status of requests that cannot be immediately supplied, were received as printed lists and also had to be entered manually onto the Libertas record, with the user being advised by email as appropriate.

Users were able to access their library account and view their requests, and their progress, by logging in using their name and a 4 digit PIN.

The result of this system and approach meant that the average delay for photocopies, that is from the time a request is completed to the item being made available at the library counter, was around 7 working days.

Anxious to ensure that service improvements could happen, the team tasked with preparing the documentation for prospective bidders to supply a new LMS wasere asked to include ILL functionality in the assessment criteria. After due process, Endeavor Information Systems Incorporated 'Voyager' LMS was selected, along with its sister ILL product CLIO. Voyager was installed and went live in February 2004. Installation of CLIO was delayed to allow staff time to learn the new LMS and the different processes and procedures involved. The Libertas licence did not expire until July 2004, so the ILL functionality was retained in the interim.

\section{Changing the lead; leading the change}

As part of the ILS staffing restructuring that took place, managers became 
aware that the changing roles would mean that the person currently delivering copyright advice and guidance, on a voluntary basis, would not be able to continue to do so. A proposal was drawn up, presented, and accepted to create a new professional post, the Document Delivery and Copyright Librarian. The post-holder would oversee strategic development and change in all aspects of the library's document delivery services, and to raise the profile of, and awareness of, copyright across the whole University - something seen as of considerable importance given the moves towards the electronic age in teaching, learning and learning support. The post was filled in May 2004, and almost immediately given the task of overseeing the switch from Libertas to CLIO, building on the preparation work done by a small crosscampus team of ILL operatives.

It was immediately apparent that the changes in the internal library staffing structure meant that the existing paper-based process needed amending. Apart from the 'loss' of the subject teams, ILL was placed in the Collection Services team which meant that operatives would also be performing acquisitions-based tasks and would have less time to key-in and/or handle requests. The best solution would be to find a way of automating some or all of the process.

In line with most html web-based LMS functionality, Voyager offered an electronic request form that would automate the process by utilising a server to server email protocol. ILL operatives could then 'import' these requests from the e-mail inbox directly into the CLIO software, check them and then use CLIO functionality to immediately email them to BLDSC in the correct format. A perfect solution to our need! 
The only drawback was that the incoming request email from Voyager could only be sent to a single email account, thereby removing from the outlying campus' ownership of their local request activity. Because this change was in line with the organisational changes already outlined, it was decided to proceed and centralise all request processing at Plymouth, leaving the smaller campuses to act as item receiving locations only.

Three request forms were developed and implemented in July 2004:

- British Library Loan Requests

- British Library Journal Article Photocopies

- British Library Book or Conference Photocopies

A copyright declaration was added to each form's header, with completion of the form being regarded as acceptance of the conditions given, thereby allowing the request to be processed. This was then followed with a personal signature being provided on another declaration upon collection of the copy. Although not required for loan requests, we decided that inclusion of the declaration in the header to that form would continue to reinforce the message and underline the importance of the declaration.

It was anticipated that there would be two major consequences of implementing this change. The loss of specialist subject knowledge and local campus knowledge in the checking process; the placing of request handling and checking in the hands of operatives formally used to only acting as copy typists or goods receiving clerks and This is a revised author's draft of an article published in the Emerald journal 'Interlending and Document Supply 2007 vol 35 issue 2 pages $15-20$. DOI: http://dx.doi.org/10.1108/02641610710728140 
who would also be using unfamiliar software; the removal of counter-signing by lecturers, especially for first year students; the opening up of the forms and the requesting process, and giving the service a higher profile by making requesting a part of the OPAC-based services, would all lead to an increase in the number of requests made by users and an increase in the number of unnecessary or duplicate requests reaching the British Library, thereby increasing the annual expenditure. This anticipated outcome was realised in the first full year of operation when expenditure on ILLs rose from $£ 48,000$ to $£ 84,000$. However, it was also anticipated that 'learned experience' of ILL operatives (we have a very low turnover of staff, with only 1 retiree in the past 4 years!); better resource training of users (now called Patrons) by the Academic Support librarians; and the growing impact of electronic resource packages, both purchased and 'free-to-access', would all result in a fall in the number of requests over time, in line with the reported experiences of other libraries who have monitored the impact of electronic resources. Again, this expectation has been realised with the year two figures showing an expenditure of $£ 72,000$.

\section{Secure Electronic Delivery}

Following a visit by British Library representatives in February 2005 it was decided to switch to their Secure Electronic Delivery (SED) service as our default delivery method, utilising the easier authentication process available with Adobe Acrobat Reader 7. Articles were printed out in the ILL office using a dedicated printer - we quickly learnt that using networked printers cut the print speed from around 20 pages per minute to around 3.5 pages per minute and that files could take up to an hour to travel around the network because of file size and the general 'busy-ness' of our computing network. We also quickly learnt to apply a simple calculation to identify This is a revised author's draft of an article published in the Emerald journal 'Interlending and Document Supply 2007 vol 35 issue 2 pages $15-20$. DOI: http://dx.doi.org/10.1108/02641610710728140 
ILDS 35.1 Titley rev 30.10.06

possible problem files. If the file size in $\mathrm{Kb}$ exceeded more than 300 times the number of pages, then there was the likelihood that the BL operator had scanned the article as an image rather than as a black \& white bitmap. These files were checked with BLDSC Customer Services before printing, as we had several instances of files taking over two hours to print.

Utilising the electronic form and changing the handling procedures for requests had cut the article photocopy average turn around time to 5 working days. Adding SED saw that turn around time drop to an average of 3 days.

\section{The critical value of PINs}

After 3 months of embedding the process and ILL staff becoming familiar with software foibles, after all software is generally never $100 \%$ perfect!, we began to look at the next obvious step - how could we deliver the SED to the desktop and remove the need to collect from the library counter? At the same time other library teams were looking at the LMS and asking questions about personal library account security and also about how we could more securely utilise some of the other features offered, e.g.: Self Issue, Media Scheduling, and Room Bookings.

The answer lay in enabling the Personal Identification Number (PIN) feature of the LMS. This would provide an additional element in the Patron log-in process, with access to personal library account information and enhanced services, such as selfissue and requesting, then requiring a University issued barcode, the PIN and your surname. Investigations also quickly discovered that this PIN would not be viewable by anyone using library staff clients, like Circulation, to access the LMS. The only This is a revised author's draft of an article published in the Emerald journal 'Interlending and Document Supply 2007 vol 35 issue 2 pages 15-20. DOI: http://dx.doi.org/10.1108/02641610710728140 
option available to library staff would be to reset the PIN. This meant that, with the right procedures in place, the PIN would be as much solely under the control of the individual as we could achieve. Additionally, to add to the perceived security of the PIN, it was noted that the system could be set to require a numeric or alphanumeric PIN of between 5 and 8 characters, with the promise that a future upgrade could even offer the possibility of up to 12 characters. This was seen as especially favourable as it meant that existing bank card PINs could not be used.

ILS decided to provide only numeric keypads at self-issue computers, so the decision was taken to set the system default PIN for all accounts to 11111 , and to make this number unselectable as a optional PIN, because it had been noted that in some PIN systems the act of changing the number rather than the setting of a different number unlocked the account. Because no enhanced services, e.g.: self issue, online renewals or requesting, would be available to any patron unless the PIN was changed from the default, this was a very effective strategy in forcing patrons to take ownership of their accounts. Because library accounts are 'locked' after three attempts to enter a PIN, library staff on the Counter and Enquiry Desk had to put in place a procedure that allows the resetting of PINs back to the default, which the patron must then change, via the OPAC, before being able to utilise services. This personal control gave us the final element needed to seriously consider the regulations for an electronic signature.

\section{Taking the plunge!}

The systems installation architecture for the LMS and ILL software called for the two services to be installed on separate servers. In setting up the ILL service, the decision This is a revised author's draft of an article published in the Emerald journal 'Interlending and Document Supply 2007 vol 35 issue 2 pages $15-20$. DOI: http://dx.doi.org/10.1108/02641610710728140 
had also been taken to control read/write access to the software by utilising a closedmembership email group, managed by the Document Delivery and Copyright

Librarian. It was felt that, because the ILL software client could be downloaded by anyone with access to the staff University software network, this offered a sensible means of controlling who could actually add or edit records. If anyone outside this group felt the urge to download and open the software it would be in 'Read Only' mode and any changes would not be saved. It was only in August 2005, when we were looking at electronic signatures, that we realised the benefits of this controlled access arrangement. Additionally, administrative access to the server was also limited to 7 people, with the server licence allowing only three to log-in at any one time and the server maintaining a log of access. Of these 7 , two are members of staff in the ILL Team, access being required for software administration - CLIO is a Microsoft Access-based product and requires regular archiving and 'compact and repair'; one is a member of the ILS Electronic Resources Development Team, who are responsible for communications with the supplier, coordinating any updating of the software and monitoring the server and its performance; the remainder are members of University computing staff who require access for hardware and systems maintenance purposes. This control and logging of access, along with the fact that the request email travels only between two internal servers regardless of the geographic location of the person generating the request, is a key part of our meeting electronic signature regulations.

The final issue to be resolved was how we could record the 'signature' within the CLIO database so that it would be stored alongside the patron information and the bibliographic information. Could we record acceptance of the copyright declaration This is a revised author's draft of an article published in the Emerald journal 'Interlending and Document Supply 2007 vol 35 issue 2 pages 15-20. DOI: http://dx.doi.org/10.1108/02641610710728140 
by a click through window process or would we have to actually record a key stroke? A study of the database identified the fact that its structure was locked and would be uneditable. However, several unused fields were identified (CLIO was developed initially for the US market and then adapted for other markets - this means that fields utilised in one geographic locality are blank in another). Of these fields the one labelled 'Verified' seemed a logical choice, especially as a corresponding field already appeared on the request checking form, and the most appropriate way to populate it was to ask the Patron to enter data during the requesting phase.

$<$ insert request checking form $>$ Page 4 in accompanying document

This is optional

Following some discussion it was decided to proceed with the Document Delivery and Copyright Librarian's suggestion that this new field be the first on the form, that it be made a required field, so that the form could not be submitted without an entry, and that Patrons be instructed to type in a positive response to the copyright declaration. The three request forms were altered accordingly.

<insert upper portion of British Library Loan Requests Form> Page 3

Because of the limits in the size of the form header, an abbreviated declaration was used, along with a hyperlink to our internal copyright pages should additional information be required, and the instruction, in bold type, "To indicate your acceptance of the Declaration, please type YES in the field below". The field title box then reinforced this instruction by stating, again in bold, "I agree (type YES)". The physical, cognitive, action of typing YES in response could then be presented as This is a revised author's draft of an article published in the Emerald journal 'Interlending and Document Supply 2007 vol 35 issue 2 pages 15-20. DOI: http://dx.doi.org/10.1108/02641610710728140 
ILDS 35.1 Titley rev 30.10.06

part our 'defence' should the need arise. This stance has since been accepted in case law in regard to emails - if you actually type your name at the bottom of a message you are cognitively signing the message and the recipient can accept this action as a signature (Pinsent Masons, 2006).

Upon receipt of the request, ILL operators were instructed to make this 'Verified' field their first check, immediately failing any requests that had either a negative or indeterminate response. (In fact, to date, we have not had to fail any for this reason, the worst cases being those in the early days who entered only $\mathrm{Y}$ - but as this was a positive response these were accepted). The response entered is then permanently recorded in the CLIO database in the same request line as the bibliographic and patron details. PINs were enabled in August 2005.

$<$ insert CLIO database structure> Pages $1 \& 2$ in accompanying document

It was decided to keep the declaration and signature process in the British Library Loan Request form, even though it is not required by copyright law. As before, it was again felt that this would present a consistent approach to patrons, would reinforce the importance of the process and would mean all patrons becoming familiar with the process more quickly. This decision had one unforeseen benefit. Because the Loan Request form was displayed as the default form after clicking on the Request button, other forms only being visible after clicking the form select arrow, patrons often used that form to enter all types of requests. The inclusion of the declaration and signature This is a revised author's draft of an article published in the Emerald journal 'Interlending and Document Supply 2007 vol 35 issue 2 pages 15-20. DOI: http://dx.doi.org/10.1108/02641610710728140 
ILDS 35.1 Titley rev 30.10.06

process meant that ILL staff could continue with the request, making the changes in their review screen, rather than deleting and asking the patron to re-enter the request on the correct form.

To the Patron, the only part of the electronic signature visible is the need to type YES in the request form. They are not cognitively aware of the fact that their logging-in to their library account is part of the process, and they are completely unaware of the systems veracity (internal server-to-server emailing and the procedures in place to keep the ILL data secure). This makes the system and process simple and unobtrusive.

\section{The penultimate step - sending to the desktop}

Almost immediately after enabling PINs a small group was established to plan the introduction of SED to the desktop. The group was chaired by the Document Delivery and Copyright Librarian and included one representative from each of the 4 four teams within the library at Plymouth who dealt directly with patrons and a representative from one of the outlying campuses. More importantly, a member of the IT Support Desk was invited. This meant that any needs could be communicated directly to the computing support and desktop teams, and that staff who received help calls from staff or students would also have an understanding of the process. This inclusion has proved vital to the successful introduction of SED to the desktop.

The Group originally met with a remit to plan for the introduction and marketing of SED to the desktop in early December 2005. However, introduction of the service was delayed until April 2006 by decisions taken by management, firstly to upgrade This is a revised author's draft of an article published in the Emerald journal 'Interlending and Document Supply 2007 vol 35 issue 2 pages $15-20$. DOI: http://dx.doi.org/10.1108/02641610710728140 
the LMS over Christmas 2005 and secondly through the establishment of a Library Consultative Committee, which provides a forum for Faculty representatives to meet and consider issues relating to the library and its services and development, and who it was felt should discuss this service development before implementation.

The direct involvement of computing staff with the process meant that the simplicity of using Adobe Reader 7, in comparison to version 6 which requires a Microsoft .net passport account or an authentication account with Adobe, was communicated to the right decision makers quickly. The evidence provided by the ILL Teams experience, who they had had to download Reader 7 direct from the Adobe website, was used to support other requests for the desktop team to upgrade the University standard from Adobe Reader 6 to version 7. Regrettably, the decision was taken to install version 7 directly onto all Open Access and teaching room computers only; and to have staff install the programme via Run Advertised Programs under their computer's Control Panel. Using this route did at least allow them to include an uninstall version 6 script when the installation programme was run, but it did mean that some staff suffered failures in the process in April and May and ILL Staff had to work hard to maintain patron faith in the value of the new service.

Aside from being a little frustrating to ILL staff, who by now knew the service worked well and who were using a laser toner cartridge and 7 reams of paper every two weeks, this delay did have a real advantage. Each member of the implementation group were able to receive training in the process using actual requests, and were then able to cascade that training to other members of their teams or campuses and again the hands-on element of this training involved downloading and printing actual This is a revised author's draft of an article published in the Emerald journal 'Interlending and Document Supply 2007 vol 35 issue 2 pages 15-20. DOI: http://dx.doi.org/10.1108/02641610710728140 
requests in real-time. The delay also allowed us to approach the Electronic Resources Development Team to provide video-streaming of the screen and mouse moves necessary to support the information that was to be provided in printed leaflets. Videos that explained "Installing Adobe Reader for staff"; "Downloading your document" and "Managing and deleting files" were produced.

Using staff unfamiliar with the process during this training period also allowed us to 'view' the whole process from the patrons' point of view. Because the link emails from the British Library would be forwarded to the patron from the ILL email account, it became apparent during this training that some reinforcement of the basic instructions contained in the library leaflet would be required. Our deliberations lead to the production of an email signature that would be added to all forwarded British Library emails. One of the big advantages of this approach to forwarding was our ability to include the URL hyperlink to the British Library's SED test document. This meant that we could reinforce good practice by getting patrons to run a 'systems' test before attempting to download the document, thereby reducing the number of times the British Library have to be contacted due to a problem caused by our own network, a faulty log-in, or a faulty install of Acrobat Reader.

$<$ insert the current signature that it is added to forwarded emails $>$ page 5

The signature has been altered over time to react to end-user problem areas.

Illustrated above is the signature in its current form. One of the key problem areas it has been used to reinforce is the modus operandi required for those using open access computers. These patrons must run the system test, download the document (if the 
test is successful), and take a print copy all within the same log-in session. The signature may yet evolve again in the near future as we are beginning to see an increase in the number of failed transactions due to patrons saving the file to a memory stick and trying to open the file with another computer. This is covered by our leaflet but we may decide to reinforce the 'please do not do this message' if the trend continues.

Overall, the introduction of SED to the desktop has been very successful, with our overall problem rate running at just under 3\% of all forwarded emails. Half of these would never have happened if the patron had read the leaflet before attempting to download the document! The service has raised the profile of ILL within the University and is perceived as a positive value-added service by students and staff. The big benefit is the speed of supply of items required. The article turn around time is now averaging 2.5 days from the time of submission of request to the receiving of the article link in their university e-mail account. A large percentage arrives in less than 2.5 daysmuch more quickly than that average, it being not all that unusual for a patron to make a request in the morning and receive the link email in the afternoon!

\section{What's next?}

Looking ahead, there is one final step available to us, that is to make use of the British Library's 'AddAddress' feature and have the link email sent directly to patron email accounts. This may not offer any further improvement in turn around and does have certain drawbacks. For instance, we would loose the added value email signature, or it would pass on email address and inbox problems to a remote organisation rather than have them dealt with locally, or it would mean a significant increase in the daily Replies Intray from the British Library as we would have to enable the 'Shipped Item' This is a revised author's draft of an article published in the Emerald journal 'Interlending and Document Supply 2007 vol 35 issue 2 pages $15-20$. DOI: http://dx.doi.org/10.1108/02641610710728140 
message report. However, eonsideration of the implications of utilising the service is not yet on our list of priorities as this final step is not supported by the current version

of CLIO. In the meantime we will continue to reinforce the process and the principles of good practice (test, download, print, and delete within the same log-in) in the hope that, when this does become an option, we will have such a well trained patron base that the introduction of 'AddAddress' can be as seamless and successful as the current process.

\section{Conclusion}

In a short period of time the University of Plymouth has moved from a paper-based and cumbersome document requesting and delivery service to one that utilises the available technology to provide an electronic-to-electronic document delivery service for over $98 \%$ of photocopy requests. Our systems set-up, following the change of LMS, provided an environment within which we could utilise electronic signatures for copyright. Our solution operates in safe and secure way with all personal information remaining within the University network at all times with only an anonymousised request being emailed to the British Library or other suppliers for fulfilment. The use of a PIN solely under the control of the individual patron also contributes significantly. The solution to the removal of a paper signature is, as far as the patron is concerned, simple and unobtrusive. If challenged we can point to the stored 'Yes' in the CLIO database and be able to make reference to the process and system security that allowed that little word to appear in the record. Until now, only one library in the UK has openly admitted to using electronic signatures for copyright (Prowse, 2004). Perhaps now the UK ILL community can take a closer look at its systems and find their own solutions to the paper trail. 
ILDS 35.1 Titley rev 30.10.06

\section{References}

Copyright, Designs and Patents Act 1988 (c. 48). London: The Stationary Office, 1988

Pinsent Masons (2006). "Court rules that an email address is not a signature", OutLaw News $13^{\text {th }}$ April 2006, available at www.out-law.com/page-6839 [last accessed: $26^{\text {th }}$ October 2006]. Being a report on case number [2006] EWHC813 (ch), the judgement of His Honour Judge Pelling QC in the case of J. Pereira Fernandez, S.A. versus Nilesh Mehta.

Prowse, S. (2004). "Recent developments in remote document supply in the UK", Interlending and Document Supply, Vol. 32 No. 2, pp.103-108.

Statutory Instrument 2002, Number 318. Electronic Communications: The Electronic Signatures Regulations 2002. London: The Stationary Office, 2002 